\title{
Left posterior hemiblock in acute myocardial infarction
}

\author{
P. Rizzon, L. Rossi, C. Baissus, J. C. Demoulin, and M. Di Biase \\ From the Division of Cardiology, University of Bari; Columbus Clinic, Milan, Italy; Division of Cardiology, \\ University of Montpellier, France; and Division of Pathology, University of Liège, Belgium
}

Fifteen cases of left posterior hemiblock associated with acute myocardial infarction were studied.

In 5 cases the left posterior hemiblock was the only intraventricular conduction defect, while in the other Io cases it was associated with complete right bundle-branch block.

Left posterior hemiblock proved to be an early complication, appearing within a few hours from the onset of the acute episode, and an ominous sign, since hospital mortality rate was 87 per cent. Cause of death was mainly pump failure.

In most of these cases there was electrocardiographic evidence of infarction involving both anterior and inferior ventricular walls.

Infarction of most or all of the ventricular septum was a common finding in the cases examined anatomically.

Histologically, acute changes involving mainly the posterior septal and midseptal fibres were observed in 6 of the 8 cases studied.

On the basis of these findings and of other published findings an alternative physiopathological mechanism for so-called left posterior hemiblock is proposed.

Expressing a widespread feeling, Rosenbaum recently stated that left posterior hemiblock 'still seems surrounded by a halo of mystery' (Rosenbaum et al., 1972).

The most disconcerting aspect of this electrocardiographic pattern is surely its rarity, especially as an acute manifestation. This justifies our poor knowledge of its electrophysiological mechanism and clinical significance. The incidence of left posterior hemiblock alone or in association with complete right bundle-branch block in large series of acute myocardial infarction is by far the lowest of all the intraventricular conduction defects, as indicated by the published figures: 0.2 per cent (Scheinman and Brenman, 1972), 0.4 per cent (Col and Weinberg, 1972), 0.3 per cent (Rizzon, Di Biase, and Baissus, 1974), for pure left posterior hemiblock; 0.4 per cent (Marriott and Hogan, 1970), 0.4 per cent (Scheinman and Brenman, 1972), 0.6 per cent (Rizzon et al., 1974) for left posterior hemiblock associated with right bundlebranch block. From a study of the published reports it also appears that only few examples of welldocumented pure left posterior hemiblock compliReceived 18 November 1974 . cating acute myocardial infarction have been described (Pryor and Blount, 1966; Shadaksharappa et al., 1968; Castellanos et al., 1970; Marriott and Hogan, I970; Slama, Motté, and Coumel, I97 I ; Col and Weinberg, 1972; Wagner and Rosenbaum, 1972).

Another important factor which contributes to our uncertainty about this condition is the absence of anatomo-histological studies on an adequate number of cases.

The aim of this report is to present our clinical, electrocardiographic, and anatomo-histological findings in 15 cases with apparent left posterior hemiblock associated with acute myocardial infarction.

\section{Subjects and methods}

Fifteen cases with typical acute myocardial infarction and electrocardiographic abnormalities compatible with the diagnosis of left posterior hemiblock, according to the criteria of Rosenbaum, Elizari, and Lazzari (1968) and Rosenbaum et al. (1972), were selected for the study. Similar electrocardiographic patterns have also been described as left inferior intraventricular block (Pryor and Blount, 1966) or posterior fascicular block (Hecht et al., 1973).

In 5 of the cases left posterior hemiblock presented 
TABLE Main clinical and electrocardiographic data from 15 patients with acute myocardial infarction and

\begin{tabular}{|c|c|c|c|c|c|}
\hline $\begin{array}{l}\text { Case } \\
\text { No. }\end{array}$ & Age & Sex & $\begin{array}{l}\text { Location } \\
\text { of the } \\
\text { myocardial } \\
\text { infarct }\end{array}$ & $\begin{array}{l}\text { Previous myocardial } \\
\text { infarction }\end{array}$ & Intraventricular conduction defects and evolution \\
\hline I & 45 & $\mathbf{M}$ & $\begin{array}{l}\text { Anterior } \\
\text { wall }\end{array}$ & $\begin{array}{l}\text { In inferior and lateral } \\
\text { wall } 20 \text { days before } \\
\text { recent episode }\end{array}$ & $\begin{array}{l}\text { Normal IVC } 5 \mathrm{hr} \text { after onset of recent episode; LPH } 3 \mathrm{hr} \\
\text { later, followed by shock; death } 16 \mathrm{hr} \text { later (terminal } \\
\text { complete AV block) }\end{array}$ \\
\hline
\end{tabular}

$\begin{array}{ccccc}2 & 53 & M & \begin{array}{c}\text { Inferior } \\ \text { wall }\end{array} & \begin{array}{c}\text { In anteroseptal wall } \\ 3 \text { days before } \\ \text { recent episode }\end{array}\end{array}$

$3 \quad 65 \quad F \quad \begin{gathered}\text { Anterior } \\ \text { wall }\end{gathered}$
wall

$4 \quad 62 \quad M \quad \begin{gathered}\text { Inferior } \\ \text { wall }\end{gathered}$

7

6

$6 \quad 72 \quad M$

$\begin{array}{cccc}7 & 85 & \text { F } & \begin{array}{c}\text { Antero- } \\ \text { septal } \\ \text { wall }\end{array} \\ 8 & 84 & \text { M } & \text { Inferior }\end{array}$

$\begin{array}{llll}8 & 84 & M & \begin{array}{r}\text { Inferio } \\ \text { wall }\end{array}\end{array}$

965 M Antero-

septal

Io $63 \quad \mathrm{M}$ Anterior wall

$70 \quad M$

Anterior and inferior wall

Anteroseptal and inferior wall $\begin{array}{llll}13 & 67 & M & \begin{array}{c}\text { Antero- } \\ \text { septal } \\ \text { wall }\end{array}\end{array}$ wall

In inferior wall 3 days before recent episode

In anterior wall $3 \mathrm{yr}$ before recent episode

No evidence

In anterior wall $7 \mathrm{yr}$ before recent episode

History of angina; $q$ waves in leads II, III, and aVF

No evidence

No coronary history but broad $q$ waves and negative $T$ waves in leads II, III, and aVF

In inferior wall $\mathrm{I}$ yr before recent episode

No evidence

No evidence except for prolonged anginal crisis $(12 \mathrm{hr}) 2$ days before recent episode In inferior wall $3 \mathrm{yr}$ before recent episode

No evidence; normal ECG I yr before recent episode

IVC $=$ Intraventricular conduction.
LPH on ECG recorded $30 \mathrm{~min}$ after onset of recent episode; I I hr later shock followed by $2:$ I, third degree, and second degree (type I) AV block; death from shock and acute pulmonary oedema (terminal cardiac asystole) $13 \mathrm{hr}$ later

LPH on ECG recorded $40 \mathrm{~min}$ after onset of the recent episode; LPH disappeared after 3 days; left ventricular failure improved by treatment; death from acute pulmonary oedema ro mth after discharge

Normal IVC on first ECG recorded $7 \mathrm{hr}$ after onset of recent episode; LPH I hr later persistent until discharge on 20th day; moderate left ventricular failure; no followup afterwards

Normal IVC 5 hours after onset of acute episode; LPH $2 \mathrm{hr}$ later; death from hyperglycaemic coma and shock $24 \mathrm{hr}$ later

LPH and RBBB on first ECG recorded $7 \mathrm{hr}$ after onset of recent episode; left ventricular failure improved with treatment; sudden death 12 days later

Complete RBBB on first ECG recorded $6 \mathrm{hr}$ after onset of recent episode; intermittent 2: I LPH $2 \mathrm{hr}$ later; death I $5 \mathrm{hr}$ later from shock (terminal cardiac asystole)

LPH, complete RBBB and second degree (type I) AV block on first ECG recorded $8 \mathrm{hr}$ after onset of acute episode; third degree AV block $2 \mathrm{hr}$ later; death from shock $16 \mathrm{hr}$ later

LPH and complete RBBB on first ECG recorded $5 \mathrm{hr}$ after onset of acute episode; shock and death from cardiac asystole $15 \mathrm{hr}$ later

Normal IVC and AV conduction $6 \mathrm{hr}$ after onset of recent episode; LPH and complete RBBB $2 \mathrm{hr}$ later; death from shock and acute pulmonary oedema II hr later (terminal cardiac asystole)

LPH and complete RBBB on first ECG recorded $8 \mathrm{hr}$ after onset of recent episode; LPH replaced by LAH after prolonged anginal pain $48 \mathrm{hr}$ later; death from shock and left ventricular failure on 7 th day (terminal cardiac asystole)

LPH and complete RBBB on first ECG recorded $6 \mathrm{hr}$ after onset of recent episode; death from shock (terminal ventricular tachycardia and fibrillation) $22 \mathrm{hr}$ later

LPH and complete RBBB on first ECG recorded $12 \mathrm{hr}$ after onset of recent episode; increased right axis deviation of QRS ro hr later; death from shock (terminal ventricular fibrillation) $4 \mathrm{hr}$ later

Complete RBBB on first ECG recorded $4 \mathrm{hr}$ after onset of acute episode while patient in shock; appearance of LPH 4 hr later in spite of circulatory improvement; relapse of shock and sudden appearance of intermittent second degree (2:1) AV block and complete AV block; death from shock (terminal ventricular asystole) $15 \mathrm{hr}$ later

LPH and RBBB on admission ECG recorded $24 \mathrm{hr}$ after onset of recurrent anginal crisis; disappearance of RBBB I hr later; death from shock Io hr after admission 
eft posterior hemiblock

\begin{tabular}{|c|c|c|c|}
\hline $\begin{array}{l}\text { Jase } \\
\text { Vo. }\end{array}$ & $\begin{array}{l}\text { IVC before } \\
\text { recent } \\
\text { episode }\end{array}$ & $\begin{array}{l}A V \text { conduction } \\
\text { before recent } \\
\text { episode }\end{array}$ & $\begin{array}{l}A V \text { conduction } \\
\text { after recent episode } \\
\text { during } I: I \text { conduction }\end{array}$ \\
\hline ! & Normal & $\begin{array}{l}\text { Transient first and } \\
\text { second degree } \\
\text { (type I) AV block } \\
\text { after previous } \\
\text { MI; afterwards } \\
\mathrm{PQ}=0.15 \mathrm{~s}\end{array}$ & First degree AV block \\
\hline : & Normal & $\begin{array}{l}\text { Normal } \\
\quad(P Q=0.10 \mathrm{~s})\end{array}$ & $\begin{array}{l}\text { Normal } \\
\qquad(P Q=0.16 \mathrm{~s})\end{array}$ \\
\hline
\end{tabular}

\begin{tabular}{|c|c|c|c|}
\hline 3 & Normal & $\begin{array}{l}\text { Normal } \\
\quad(P Q=0.12 \mathrm{~s})\end{array}$ & $\begin{array}{l}\text { Normal } \\
\qquad(P Q=0.12 \mathrm{~s})\end{array}$ \\
\hline 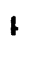 & Normal & $\begin{array}{l}\text { Normal } \\
\qquad(P Q=0.15 \mathrm{~s})\end{array}$ & $\begin{array}{l}\text { Normal } \\
\qquad(P Q=0.16 \mathrm{~s})\end{array}$ \\
\hline ; & Unknown & Unknown & Normal \\
\hline 5 & $\begin{array}{l}\text { LAH; } \\
\quad \text { incomplete } \\
\text { RBBB }\end{array}$ & $\begin{array}{l}\text { Normal } \\
\quad(P Q=0.16 \mathrm{~s})\end{array}$ & $\begin{array}{c}\text { First degree } \\
\text { AV block }\end{array}$ \\
\hline 7 & Unknown & Unknown & First degree AV block \\
\hline 3 & Unknown & Unknown & Unknown \\
\hline$\exists$ & Unknown & Unknown & Normal \\
\hline 10 & Unknown & Unknown & Normal \\
\hline II & Unknown & Unknown & $\begin{array}{l}\text { Normal during LPH } \\
\text { and RBBB; slightly } \\
\text { prolonged (PQ= } \\
\text { O.20 s) after } \\
\text { appearance of LAH } \\
\text { Normal }\end{array}$ \\
\hline
\end{tabular}

13 RBBB Normal

\begin{tabular}{|c|c|c|}
\hline I4 & $\begin{array}{c}\text { Normal } \\
\text { I yr } \\
\text { before }\end{array}$ & $\begin{array}{c}\text { Normal } \\
\text { I yr } \\
\text { before }\end{array}$ \\
\hline
\end{tabular}

Unknown Unknown Normal
$P Q=0.14 s$ on first ECG; Ist degree AV block after increased right axis deviation of QRS Normal

as an isolated intracardiac defect while in the other ro it presented in association with right bundle-branch block.

It was possible to perform an anatomical study in 9 cases: 2 with isolated left posterior hemiblock and 7 with left posterior hembilock associated with right bundle-branch block. In all these cases but one, a histological examination of the conduction system, excised from the heart in a single block, was carried out on serial sections (every $150-200 \mu$ ) using the technique of Lenègre modified by Rossi (1969) in 5 cases, and that of Demoulin and Kulbertus (1972) in 3 cases.

The morphological criteria used for assessing whether the histological changes seen were responsible for a defect of conduction were based on the following considerations. In chronic cases the correlation of histological change and conduction defect is soundly based upon the presence of disrupting injuries to the specific myocardium; in acute cases only the most severe lesion, namely necrosis, could be regarded as a certain cause of conduction blocks. Lesser cytological changes, like cloudy swelling, vacuolization (even with indistinguishable myofilaments), haemorrhage, and local leucocytic infiltration have not been considered certain causes of impaired conduction (Ekelund et al., I972). Extensive necrosis of the left bundle-branch or of its radiations in acute septal infarction is far from common. In the majority of such cases the specific fibres of the branch are apparently less damaged by acute ischaemia than the underlying myocardium, probably for various reasons, such as their subendocardial location and the inherent possibility of a vicarious transendocardial oxygenation, and the lower rate of oxygen consumption of the conducting fibres, when compared with the working myocardium (Hackel et al., 1972). Therefore, when examining the conduction system and the left bundle-branch in particular, for evidence of acute conduction disturbances from recent infarction, it is not possible to consider exclusively the classical correlation between irreversible interrupting lesions and established block; it is necessary rather to take into account also those pictures of reversible, and sometimes elusive changes, which, had the patient survived, could eventually have resulted in anatomical functional restitutio ad integrum.

\section{Results}

The main clinical and electrocardiographic data are represented in the Table. Some illustrative electrocardiographic features are shown in Fig. I to 4.

\section{Localization of infarction}

Four of the five cases with left posterior hemiblock alone (Cases I to 4) had had a previous infarct involving the inferior wall in 2 cases and the anterior wall in the other 2 , which apparently did not affect intraventricular conduction before the acute myocardial infarct responsible for the conduction defect. The localization of the acute myocardial infarct was, in the anterior wall in the 2 cases with a 
(a)

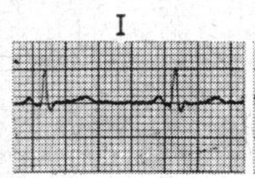

aVR

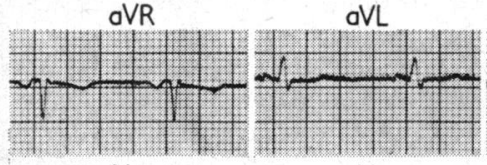

$V_{1}$
II

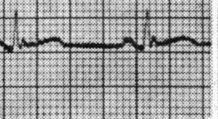

aVL
III

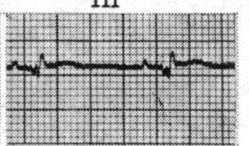

OVF

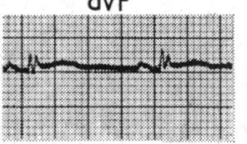

$\mathrm{V}_{3}$

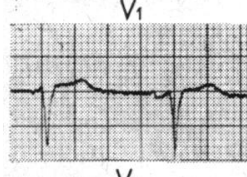

$V_{4}$

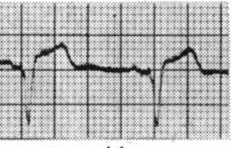

$V_{5}$

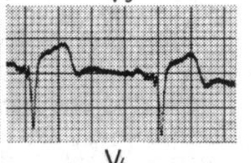

$V_{6}$

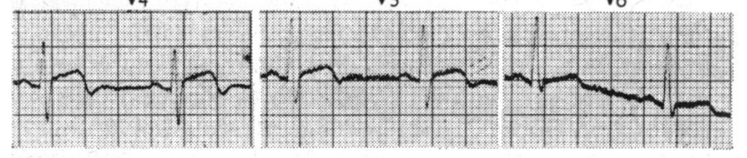

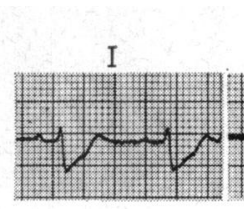

aVR

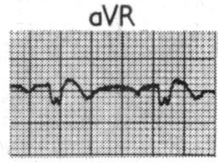

$V_{1}$

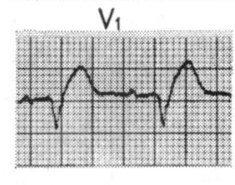

$V_{4}$

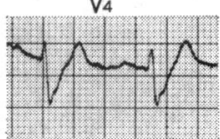

(b)

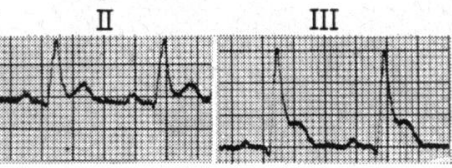

OVL
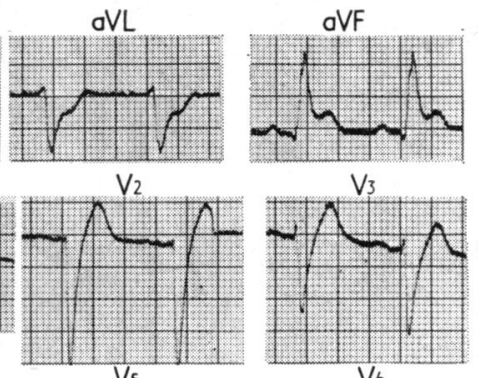

Vo
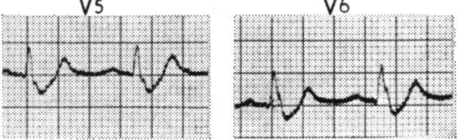

(C)

8.30p.m.

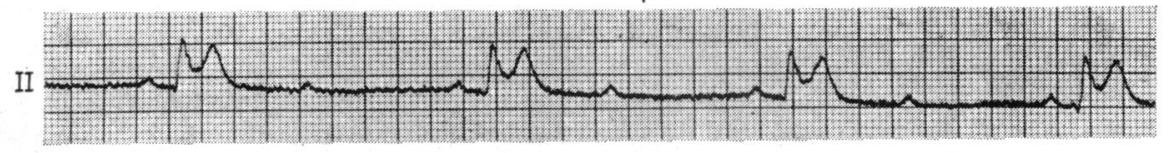

9 p.m.

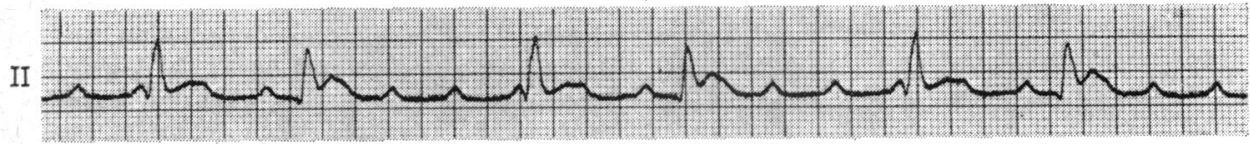

9.15 p.m.

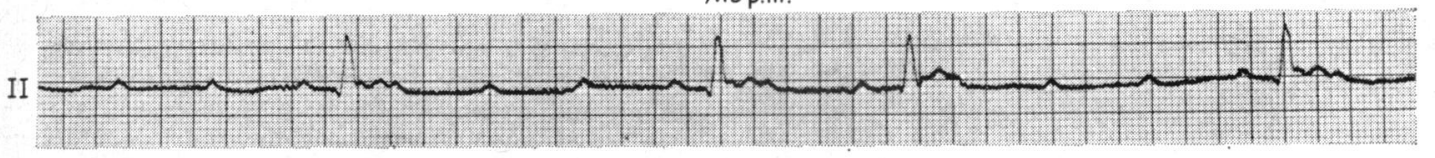

9.30 p.m.

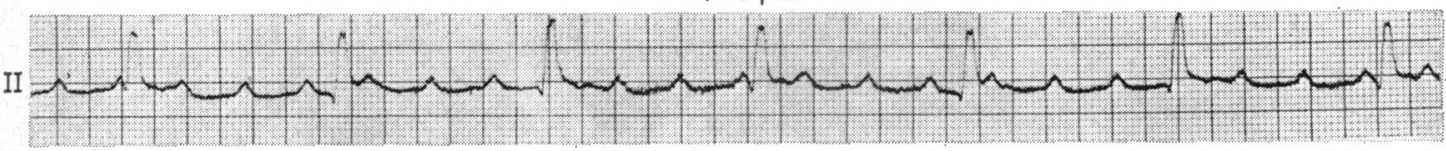

10 p.m.

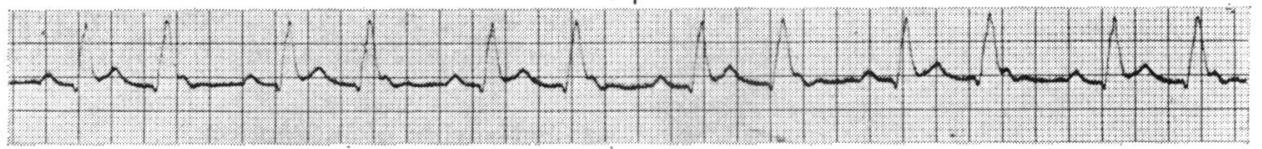

27-8-73

FIG. I Case 2 a) 24 August 1973. Acute myocardial infarction of the anteroseptal wall with normal intraventricular conduction. b), 27 August 7 a.m.: Acute myocardial infarction of the inferior wall with left posterior hemiblock. c) 8.30 p.m. to 10 p.m.: 2:I atrioventricular block in the top tracing; high degree atrioventricular block in the second and third strips; complete atrioventricular block in the fourth strip; second degree type I atrioventricular block in the bottom tracing. No changes in the $Q R S$ duration and pattern are observed when the atrioventricular block becomes complete. 


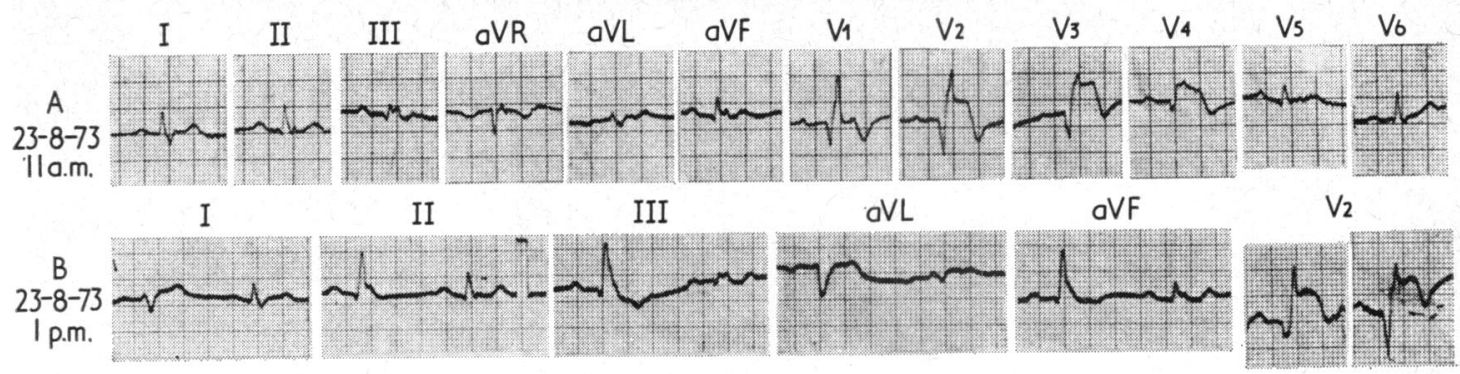

II

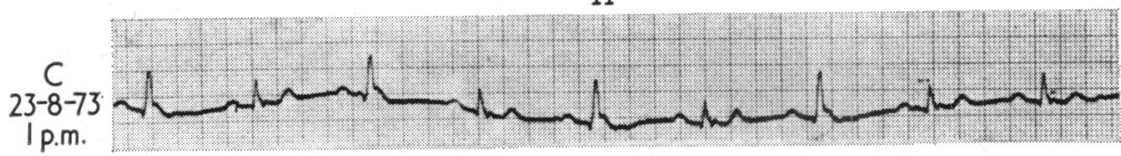

oVL

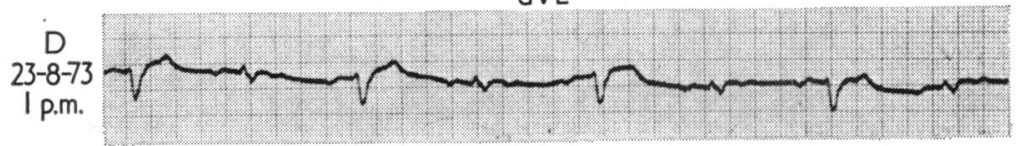

aVF

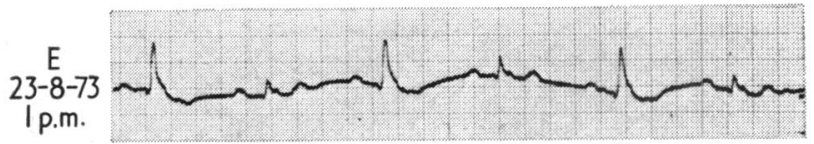

FIG. 2 Case 7 A) Acute myocardial infarction of the anteroseptal wall, old infarction of the inferior wall, and right bundle-branch block. B-E). Appearance two hours later of an intermittent 2:I left posterior hemiblock.

previous inferior localization and in the inferior wall in the 2 cases with previous anterior localization. Only Case 5 developed left posterior hemiblock after his first acute myocardial infarct which involved the inferior wall.

Of the Io with left posterior hemiblock and right bundle-branch block (Cases 6 to 15), 5 had clinical and/or electrocardiographic evidence of a previous myocardial infarction, which involved the inferior wall in the 3 cases with anterior localization of the new acute infarct and the anterior wall in the 2 cases with inferior localization of the acute infarct. In 3 cases the localization of the acute myocardial infarct was simultaneously in the anteroseptal and inferior walls. Only 2 cases had infarcts localized to a single wall, the anterior wall in one and the inferior wall in the other.

\section{Time of onset of left posterior hemiblock}

In 8 cases (Cases I to 5, and 7, I0, and I4), the left posterior hemiblock became manifest after initial observation of the patients. In 5 of these, it appeared as an isolated pattern, in 2 there was a pre-existent right bundle-branch block, and in $I$ it appeared simultaneously with a right bundle-branch block. The time of onset of the left posterior hemiblock in these cases ranged between 30 minutes and 8 hours from the onset of the acute myocardial infarct. In the other 7 cases $(6,8,9,1$ I to 13 , and 15), the left posterior hemiblock in association with right bundle-branch block was already present on the admission electrocardiogram which was recorded within the first 12 hours from the onset of the acute myocardial infarct.

\section{Evolution}

Of the 15 patients, 13 died while still in hospital: II of them died in the coronary care unit within the first 48 hours of the onset of the acute attack. The cause of death was shock with terminal ventricular fibrillation or cardiac asystole in 8, shock and acute ventricular failure with terminal cardiac asystole in 3 , and complete atrioventricular block followed by shock in I case. One patient died suddenly on the I2th day after being moved to the general ward. Two patients were discharged with a condition of moderate left ventricular failure. One of them, whom we could follow up, died at home from acute pulmonary oedema ro months after discharge. 
(a)

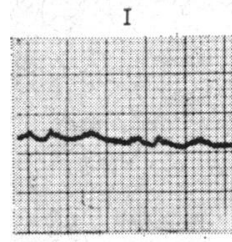

aVR

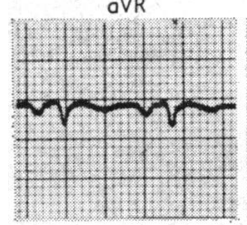

$V_{1}$

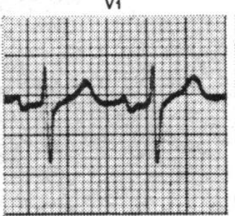

$V_{4}$

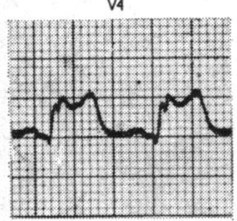

II

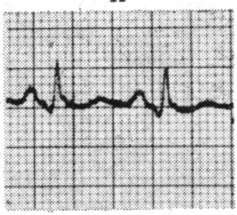

$\mathrm{aVL}$

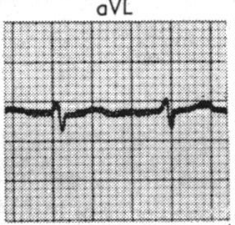

$V_{2}$

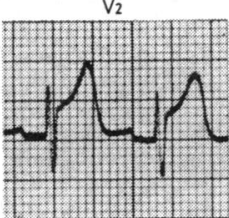

$V_{5}$

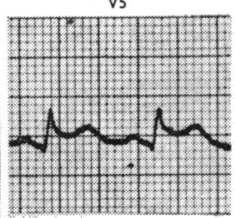

III

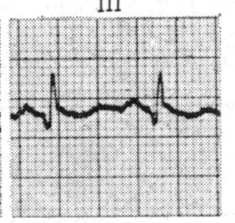

oVF

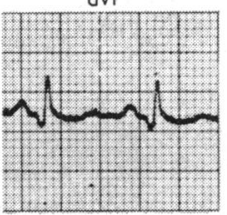

$V_{3}$

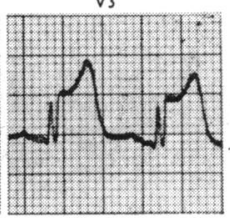

$V_{6}$

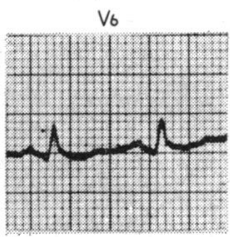

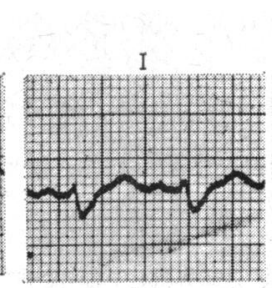

QVR

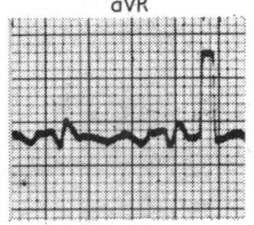

$V_{1}$

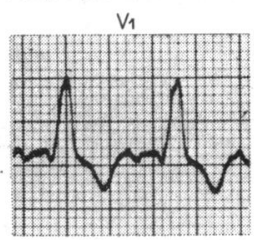

$V_{4}$

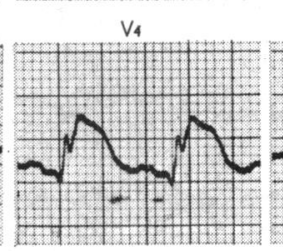

(b)

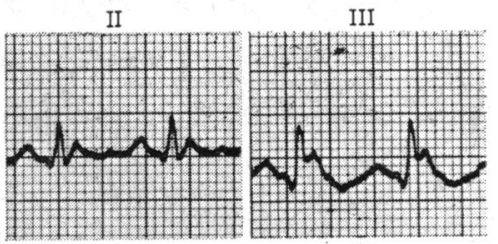

aVF

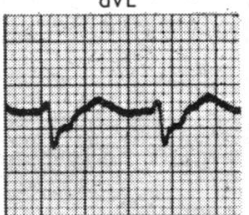

$V_{2}$

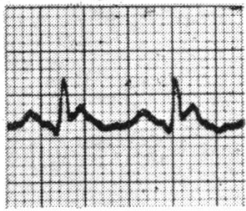

$V_{3}$

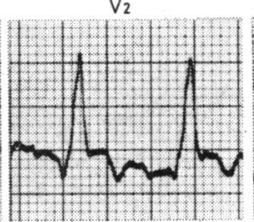

$V_{5}$

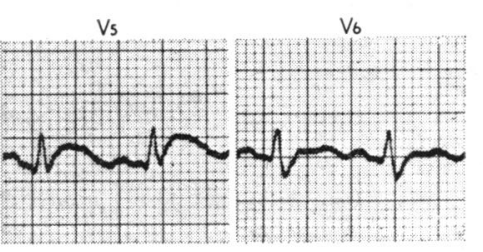

FIG. 3 Case Io a) Old myocardial infarction of the inferior wall, acute myocardial infarction of the anterior wall with normal intraventricular conduction. b) Appearance 2 hours later of right bundle-branch block with left posterior hemiblock.
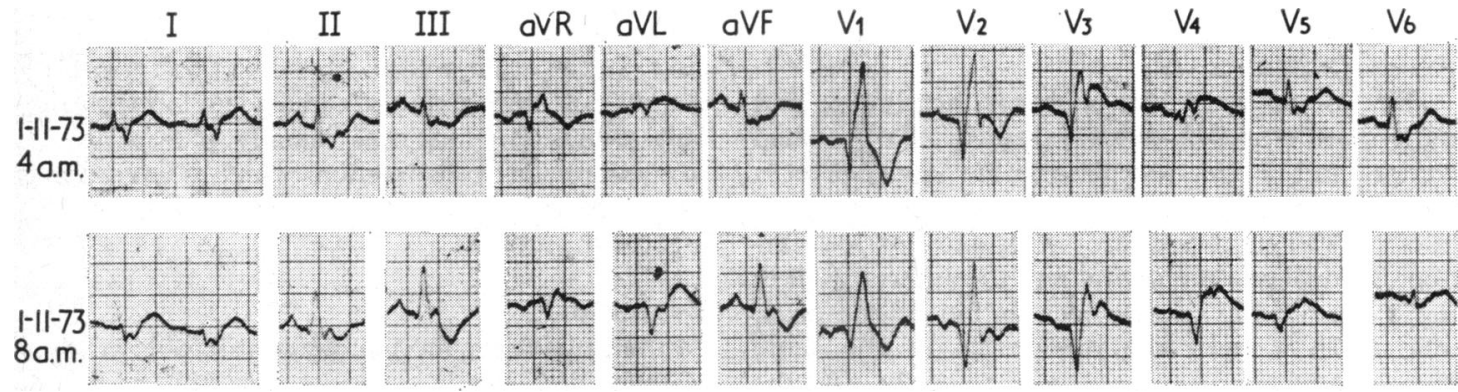

FIG. 4 Case 14: Top strip showing acute myocardial infarction of the anteroseptal wall with right bundle-branch block; bottom strip showing the appearance of left posterior hemiblock four hours later.

\section{Complete atrioventricular block}

Of the 5 cases with pure left posterior hemiblock, 2 developed complete atrioventricular block. The first (Case I) had first degree atrioventricular block (the same patient, on the occasion of a previous myocardial infarction of the inferior wall, had already experienced a transient episode of first and second degree (type I) atrioventricular block); the evolution was towards shock and a few hours later complete atrioventricular block with a slow right ventricular rhythm was observed as a terminal event. The second patient (Case 2) who had an acute 

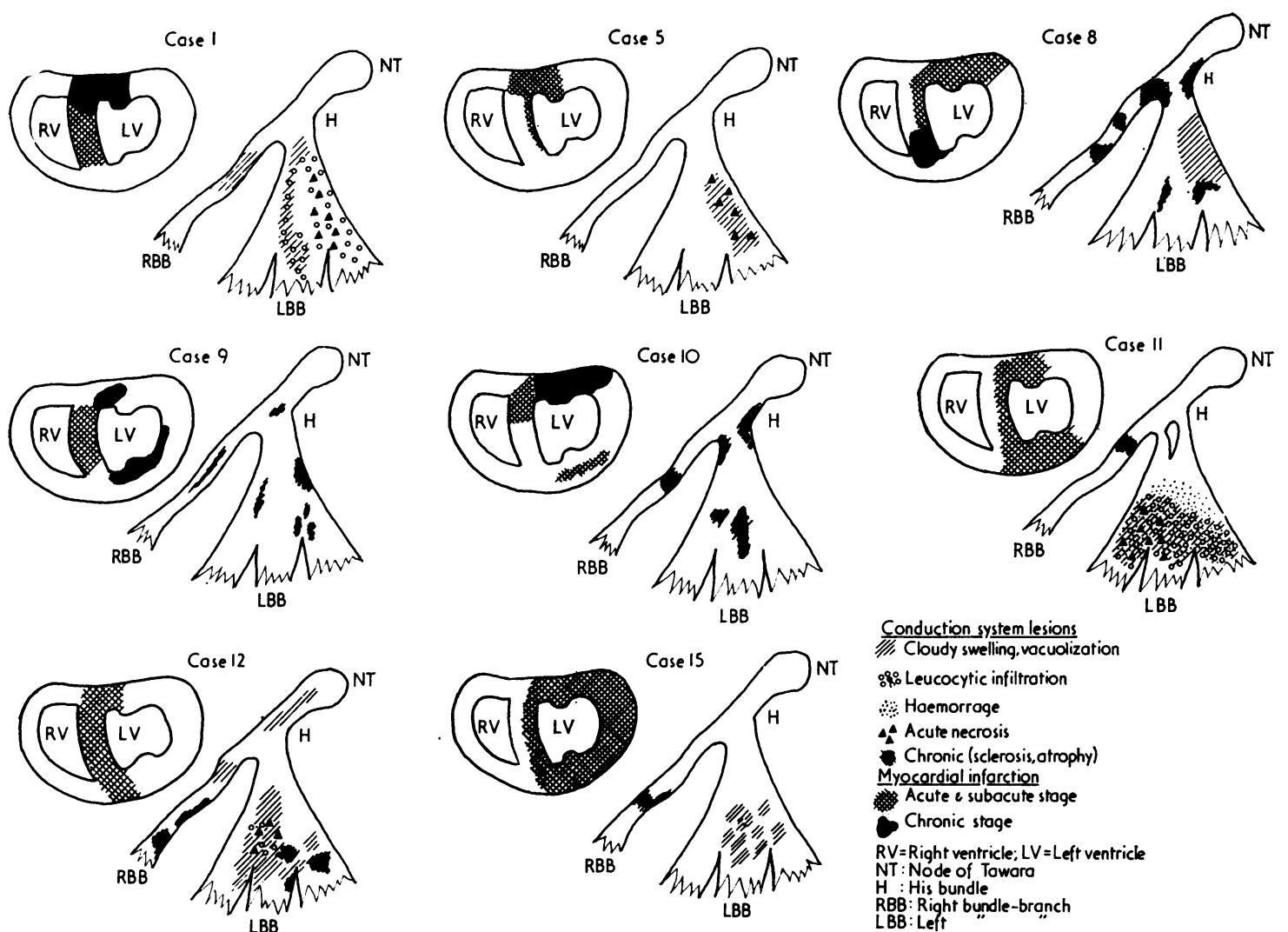

FIG. 5 Schematic representation of the histological changes affecting the myocardium (left) and the intraventricular conduction system (right) in 8 cases of left posterior hemiblock.

myocardial infarct of the anterior wall followed shortly afterwards by a second acute myocardial infarct of the inferior wall, presented, after a few hours of shock, a sequence of $2: 1$, third degree, and second degree (type I) atrioventricular block. During complete atrioventricular block the QRS complexes maintained the same pattern and duration as that of the conducted beats.

Of the ro cases with left posterior hemiblock associated with right bundle-branch block, 2 showed complete atrioventricular block. In the first (Case 8), with acute myocardial infarction of the inferior wall, second degree (type I) atrioventricular block was present on admission, followed shortly afterwards by complete atrioventricular block which did not produce any modification in the pattern or duration of the QRS complexes. In the second case (Case 14) with acute myocardial infarction of the anterior wall an unheralded intermittent second degree $(2: \mathrm{I})$ and intermittent complete atrioventricular block was observed. In this case also the QRS complexes of the escape rhythm were identical in duration and pattern to the conducted complexes.

\section{Pathological findings}

Severe (obstructive or subobstructive) atherosclerotic changes involving the three main coronary vessels (Cases I, II, I2, and I5) or the left anterior descending artery and the right coronary artery (Cases $5,8,9$, 10, and 13) were found in all 9 cases examined at necropsy.

The localization of the myocardial infarct and the main histopathological features of the intraventricular conduction system in 8 cases are schematically represented in Fig. 5. As shown here the left bundle-branch was found to have a single root in 7 cases and a double one in I case, and to fan out into diffusely interweaving strands, with some tendency to regroup into 3 (anterior, middle, and posterior) main areas of distribution in all cases. 
Pulmonary vascular changes compatible with acute or chronic pulmonary hypertension, as well as significant right ventricular hypertrophy, were not present in any case.

\section{Discussion}

The first significant finding which emerges from the study of our material is the extent and localization of the myocardial damage. In 12 of our cases there was electrocardiographic evidence of infarction of the anterior and inferior walls, which implies a failure of both the sources of blood supply to the ventricular septum, while in only 3 cases the involvement was confined exclusively to the anterior wall (I case) and to the inferior wall ( 2 cases).

The electrocardiographic data were confirmed by the anatomical findings which showed that infarction involving the entire ventricular septum or a large portion of it was present in these cases as a consequence of a severe two- or three-vessel coronary atherosclerotic disease.

These observations are wholly in agreement with those of the few previously studied cases (Scanlon, Pryor, and Blount, 1970; Scheinman and Brenman, 1972; Col and Weinberg, 1972). tion.

Some additional clinical findings deserve atten-

a) Left posterior hemiblock alone or in association with right bundle-branch block is an early complication, since it appeared within a few hours and sometimes within a few minutes of the onset of the acute episode.

b) Left posterior hemiblock is an ominous sign, the mortality rate being 87 per cent. Death mostly occurred within 48 hours from the onset of the acute myocardial infarct as a consequence of shock alone or associated with acute left ventricular failure. Electrical instability was probably the cause of death in only one patient who died suddenly on the 12th day, while in another complete atrioventricular block could have been responsible since it preceded the appearance of the shock. Thus, our findings seem to prove mortality to be mainly related to the early appearance of a severe pump failure. This evolution is easily explained by the postmortem findings showing a severe two- or three-vessel coronary disease and extensive myocardial damage. Only 2 patients survived. Nevertheless, both had left ventricular failure still present when discharged from the hospital, and I of them died Io months later from acute pulmonary oedema. Our findings of such a high mortality are in agreement with those of other series (Scheinman and Brenman, 1972; Voridis et al., 1973; Col and Weinberg, 1972; Castellanos et al., 1970). c) Some authors (Castellanos et al., 1970) have reported a high incidence of an atrioventricular block in cases of acute myocardial infarction with left posterior hemiblock and right bundle-branch block. Third degree atrioventricular block appeared in 4 of our cases $(27 \%)$. Only in one case, however, did the atrioventricular block show features in keeping with a possible intraventricular mechanism, i.e. a sudden appearance of complete block and a slow ventricular rhythm, with modification of the pattern and duration of the QRS complexes. In the other 3 cases (I with pure left posterior hemiblock and 2 with left posterior hemiblock and right bundle-branch block) progression from a second degree atrioventricular block (type $I$ in 2 cases, 2:I in one case) to complete atrioventricular block was observed. Moreover, in all 3 cases the QRS complexes of the escape rhythm were identical in duration and pattern to the conducted complexes. All these observations favour a junctional rather than an intraventricular localization of the block. Apart from the localization of the complete atrioventricular block it should also be stressed that in one case it occurred as a primary complication, while in the other cases it developed in the course of severe shock.

The study of the morphological findings and their clinico-pathological evaluation provided further interesting information. The anatomo-histological survey of the left bundle-branch in our cases confirms the results of recent studies (Rossi, 1969, 1972; Demoulin and Kulbertus, 1972; Kulbertus, 1972; Demoulin et al., 1975, unpublished data), showing the presence of a common pattern for the distribution of the conduction tissue over the septal area: the fibres of the left bundle-branch fan out quickly into diffuse interweaving strands, with some tendency to regroup more distally into three main areas of distribution, i.e. anterior, middle, and posterior septal areas. These data are in agreement with the electrophysiological findings of Durrer et al. (1970).

In attempting a clinico-pathological evaluation of our cases we were conscious of some inherent limitations. The first is the fact that only 3 cases (Cases I, 5 , and 10) had a proven postinfarction left posterior hemiblock, while in the other 5 (Cases 8, 9, II, I2, and 15) we do not know whether we are dealing with an acute or a chronic left posterior hemiblock. The second is the short lapse of time between the onset of acute myocardial infarction and death, which may be too short, should the left posterior hemiblock be a recent manifestation, to allow the functional damage to reveal itself as a definite morphological change. Thus, the possible absence (Cases 9 and ro) of acute histological damage to the 
conduction fibres cannot rule out some functional ischaemic mechanism for the block.

The other 6 (Cases I, 5, 8, II, I2, and 15), however, presented acute histological changes, associated in Cases 8 and 12 with chronic lesions, affecting the conduction fibres of the posterior septal area in 2 (Cases 5 and 8) and the conduction fibres of the posterior septal and midseptal areas in 4 (Cases I, II, I2, and 15). Case 15, with left anterior hemiblock replacing the initial pattern of left posterior hemiblock, also presented acute severe damage of the conduction fibres of the anterior septal area.

Dealing with the interpretation of the most disconcerting aspect of left posterior hemiblock, i.e. its rarity, the following data that arose from our study are of interest:

I) the almost constant association of left posterior hemiblock with severe coronary disease affecting both the anterior and posterior blood supply to the ventricular septum;

2) the consequent extensive ischaemic damage of the greater part of the ventricular septum or at least of its middle and posterior thirds;

3) themode of subdivision of the left bundle-branch and of distribution of its radiations to the septum;

4) the acute histopathological changes of the left conduction system affecting in 4 of the 6 cases not only the posterior septal fibres but also, to a different extent, the midseptal fibres.

In the light of these data one may hypothesize that structural or functional damage affecting only the posterior radiations of the left bundle-branch, owing to the rich anastomosis between the midseptal and the posterior radiations, cannot be responsible - unless so diffuse as to involve most of the conduction fibres - for activation of the inferior wall sufficiently delayed to produce right axis deviation compatible with the current criteria of socalled left posterior hemiblock, while it could explain a slighter degree of right axis deviation. In most cases pronounced right axis deviation is probably dependent on coexisting damage of the midseptal and posterior septal fibres. This type of damage implies acute insufficiency of both the anterior and posterior circulation; in both cases the result is an extensive septal infarction which also accounts for the frequent involvement of the right bundle-branch and for the high mortality; septal damage of this extent is unlikely to spare the anterior fascicle, which is the structure more easily and severely involved by ischaemia of the anterior wall; should the functional damage of the anterior fibres prevail over that of the posterior ones, the result would be left anterior hemiblock instead of left posterior hemiblock.

This interpretation has the advantage of sup- porting, rather than conflicting with previous morpho-functional arguments in this field, while indicating the need for reconsideration of the concept and terminology of the so-called left posterior hemiblock.

\section{References}

Castellanos, A., Maytin, O., Arcebal, A. G., and Lemberg, L. (1970). Significance of complete right bundle-branch block with right axis deviation in absence of right ventricular hypertrophy. British Heart fournal, 32, 85.

Col, J. J., and Weinberg, S. L. (1972). The incidence and mortality of intraventricular conduction defects in acute myocardial infarction. American fournal of Cardiology, 29, 344 .

Demoulin, J. C., and Kulbertus, H. E. (1972). Histopathological examination of concept of left hemiblock. British Heart fournal, 34, 807.

Demoulin, J. C., Rossi, L., Rizzon, P., and Kulbertus, H. E. (1975). Maladie artérielle coronaire et blocs segmentaires de la branche gauche-une étude histopathologique. Unpublished data.

Durrer, D., van Dam, R.Th., Freud, G. E., Janse, M. J., Meijler, F. L., and Arzbaecher, R. C. (1970). Total excitation of the isolated human heart. Circulation, 4I, 899.

Ekelund, L. G., Moberg, A., Olsson, A. G., and Orö, L. (1972). Recent myocardial infarction and the conduction system. A clinico-pathological correlation. British Heart fournal, 34, 774 .

Hackel, D. B., Wagner, G., Ratliff, N. B., Cies, A., and Estes, E. H. (1972). Anatomic studies of the cardiac conducting system in acute myocardial infarction. American Heart fournal, 83, 77.

Hecht, H. H., Kossmann, C. E., Childers, R. W., Langendorf, R., Lev, M., Rosen, K. M., Pruitt, R. D., Truex, R. C., Uhley, H. N., and Watt, T. B. (1973). Atrioventricular and intraventricular conduction. Revised nomenclature and concepts. American fournal of Cardiology, 31, 232.

Kulbertus, H. E. (1972). Contribution à l'étude des blocs ségmentaires de la branche gauche du faisceau de His et de leurs associations avec le bloc de branche droite. Thèse, University of Liège.

Marriott, H. J. L., and Hogan, P. (1970). Hemiblock in acute myocardial infarction. Diseases of the Chest, 58, 342.

Pryor, R., and Blount, S. G. (1966). The clinical significance of true left axis deviation. Left intraventricular blocks. American Heart Fournal, 72, 391.

Rizzon, P., Di Biase, M., and Baissus, C. (1974). The intraventricular conduction defects in acute myocardial infarction. British Heart fournal, 36, 660.

Rosenbaum, M. B., Elizari, M. V., and Lazzari, J. O. (1968). Los Hemibloqueos. Ed. Paidos, Buenos Aires.

Rosenbaum, M. B., Elizari, M. V., Lazzari, J. O., Kratz, A., and $\mathrm{Da}$ Ruos, H. O. (1972). The clinical causes and mechanism of intraventricular conduction disturbances. In Advances in Electrocardiography, p. 145. Ed. by R. C. Schlant and J. W. Hurst. Grune and Stratton, New York.

Rossi, L. (1969). Histopathologic Features of Cardiac Arrhythmias. Casa Editrice Ambrosiana, Milan.

Rossi, L. (1972). Histopathology of the conducting system. Giornale Italiano di Cardiologia, 2, 484.

Scanlon, P. J., Pryor, R., and Blount, S. G. (1970). Right bundle-branch block associated with left superior or inferior intraventricular block. Circulation, 42, 1135. 
Scheinman, M., and Brenman, B. (1972). Clinical and anatomic implications of intraventricular conduction blocks in acute myocardial infarction. Circulation, 46, 753.

Shadaksharappa, K. S., Kalbfleisch, J. M., Conrad, L. L., and Sarkar, N. K. (1968). Recognition and significance of intraventricular block due to myocardial infarction (periinfarction block). Circulation, 37, 20.

Slama, R., Motté, G., and Coumel, P. (I97I). Les Blocs Auriculo-ventriculaires. J. B. Baillière, Paris.

Voridis, E., Plessas, S., Mallios, K., and Cokkinos, D. (1973).
Blocs complets droits et bifasciculaires au cours de la phase aiguë de l'infarctus du myocarde. Archives des Maladies du Coeur et des Vaisseaux, 66, I 193.

Wagner, R., and Rosenbaum, M. B. (I972). Transient left posterior hemiblock. Association with acute lateral myocardial infarction. American fournal of Cardiology, 29, 558.

Requests for reprints to Professor P. Rizzon, Divisione di Cardiologia, Clinica Medica I', Policlinico, Università, 70124 Bari, Italy. 